\title{
Hubungan antara sindrom metabolik dengan kebugaran jasmani pada lanjut usia
}

\author{
Prijo Sudibjo*, Cerika Rismayanthi, Krisnanda Dwi Apriyanto \\ Program Studi Ilmu Keolahragan, Fakultas Ilmu Keolahragaan, Universitas Negeri Yogyakarta, \\ Jalan Colombo No.1, Yogyakarta, 55281, Indonesia. \\ * Corresponding Author. Email: prijo_sudibyo@uny.ac.id
}

Received: May 31, 2021; Accepted: August 30, 2021; Published: September 25, 2021

\begin{abstract}
Abstrak: Prevalensi sindrom metabolik pada lansia cukup tinggi. Sindrom metabolik dapat berpotensi mempengaruhi kapasitas fisik lansia dalam hal ini kebugaran kardiorespirasi, kelenturan sendi, keseimbangan dan kekuatan otot. Penelitian ini bertujuan untuk mengetahui hubungan antara sindrom metabolik dengan kebugaran kardiorespirasi, fleksibilitas, kekuatan, dan keseimbangan pada lansia. Penelitian ini merupakan penelitian cross sectional dengan teknik consecutive sampling pada 118 lansia di Yogyakarta. Sindrom metabolik ditetapkan berdasarkan kriteria diagnosis dari Adult Treatment Panel. Instrumen yang digunakan untuk mengumpulkan data adalah tes jalan 6 menit (6-minute walking test), sit and reach, hand grip dynamometer, leg and back dynamometer dan berdiri satu kaki. Teknik analisis dengan menggunakan uji korelasi Spearman. Hasil dari penelitian menunjukkan bahwa sebanyak 32 lansia mengalami sindrom metabolik. Tujuh puluh dari 118 orang memiliki data yang lengkap untuk analisis korelasi. Terdapat korelasi antara sindrom metabolik dengan kekuatan otot tungkai/leg strength $(\mathrm{r}=-0,295$, $\mathrm{p}=0,013)$ dan keseimbangan $(\mathrm{r}=-0,282, \mathrm{p}=0,018)$, namun tidak ada korelasi antara sindrom metabolik dengan kekuatan peras tangan/hand grip, kekuatan otot punggung/back strength $(\mathrm{r}=-0,101, \mathrm{p}=0,405)$, kebugaran kardiorespirasi $(\mathrm{r}=-0,197, \mathrm{p}=0,103)$ dan fleksibilitas $(\mathrm{r}=-0,084, \mathrm{p}=0,488)$. Dapat disimpulkan bahwa lansia yang terdiagnosis mengalami sindrom metabolik cenderung mengalami pelemahan kekuatan tungkai dan penurunan keseimbangan. Oleh karenanya, lansia perlu melakukan aktivitas fisik untuk meningkatkan kekuatan otot tungkai dan keseimbangan.
\end{abstract}

Kata Kunci: sindrom metabolik, kebugaran, lansia

\section{The Correlation between metabolic syndrome and physical fitness in elderly}

Abstract: The prevalence of metabolic syndrome in the elderly is quite high. One way to prevent metabolic syndrome is by being physical active. Physical activity can also improve cardiorespiratory fitness, joint flexibility, balance and muscle strength. This study aimed to determine the relationship between metabolic syndrome and cardiorespiratory fitness, flexibility, strength, and balance in the elderly. This study was a cross sectional study with a consecutive sampling technique on 118 elderly people in Yogyakarta. Metabolic syndrome was defined based on the diagnostic criteria from the Adult Treatment Panel. The instruments used to collect the data were a 6-minute walking test, sit and reach, hand grip dynamometer, leg and back dynamometer and standing on one leg. The analysis technique used the Spearman correlation test. The results of the study showed that 32 elderly had metabolic syndrome. Seventy out of 118 people had complete data for correlation analysis. There was a correlation between metabolic syndrome and leg muscle strength $(r=$ -0.295, $p=0.013)$ and balance $(r=-0.282, p=0.018)$, but there was no correlation between metabolic syndrome and hand grip strength. back muscle strength $(p=0.405)$, cardiorespiratory fitness $(p=0.103)$ and flexibility $(p=0.488)$. It can be concluded that the elderly who are diagnosed with metabolic syndrome tend to experience weakened leg strength and decreased balance. Therefore, the elderly need to do physical activity to improve leg muscle strength and balance.

Keywords: metabolic syndrome, physical fitness, elderly

How to Cite: Sudibjo, P., Rismayanthi, C., \& Apriyanto, K.D. (2021). Hubungan antara sindrom metabolik dengan kebugaran jasmani pada lansia. Jurnal Keolahragaan, 9 (2), 159167. doi: https://doi.org/10.21831/jk.v9i2.41007 
Jurnal Keolahragaan 9 (2), 2021 - 160

Prijo Sudibjo, Cerika Rismayanthi, Krisnanda Dwi Apriyanto

\section{PENDAHULUAN}

Sindrom metabolik diartikan sebagai gangguan metabolik kompleks akibat dari obesitas yang terus meningkat (Widjaya, 2004). Banyak ahli berpendapat tentang pengertian dari sindrom metabolik yang didasarkan pada hasil penelitian terkini, akan tetapi para ahli setuju bahwa sindrom metabolik ditandai oleh obesitas, hipertensi, dislipidemia dan resistensi insulin (Khan et al., 2005). Penting untuk mengetahui komponen utama sindrom metabolik bagi seseorang, agar selalu sadar kesehatan dan jika salah satu faktor sindrom metabolik menyerang maka dapat diambil Tindakan dengan bijaksana. Dengan demikian, mengetahui gejala sindrom metabolik lebih awal dapat mencegah seseorang masuk dalam beberapa komplikasi.

Pengertian dari sindrom metabolik itu sendiri telah diartikan oleh beberapa badan ataupun organisasi kesehatan, diantaranya badan kesehatan dunia atau World Health Organization (WHO), National Cholesterol Education Program Third Adult Treatment Panel (NCEP ATP-III) dan International Diabetes Federation (IDF). Ketiga definisi tersebut memiliki komponen utama yang sama dengan penentuan kriteria yang berbeda. Berdasarkan definisi dari International Diabetes Federation (IDF) bahwa seseorang dapat disebut memiliki sindrom metabolik jika mempunyai kriteria: obesitas sentral (indeks massa tubuh (IMT) $>30 \mathrm{~kg} / \mathrm{m}^{2}$ ) ditambah dua dari empat faktor berikut: (1) peningkatan trigliserida ( $\geq 150 \mathrm{mg} / \mathrm{dL}(1.7 \mathrm{mmol} / \mathrm{L}))$, (2) penurunan kolesterol high density lipoprotein (HDL) $(<40$ $\mathrm{mg} / \mathrm{dL}$ untuk pria; $<50 \mathrm{mg} / \mathrm{dL}$ untuk wanita), (3) peningkatan tekanan darah (sistolik $\geq 130$ atau diastolik $\geq 85 \mathrm{~mm} \mathrm{Hg}$ ) dan (4) peningkatan glukosa darah puasa ( $\geq 100 \mathrm{mg} / \mathrm{dL}(5.6 \mathrm{mmol} / \mathrm{L}))$ (IDF, 2006). Senada dengan pendapat Kaur (2014), beberapa kriteria sindrom metabolik mencakup: (1) obesitas sentral, (2) hiperglikemia, (3) hipertensi dan (4) dislipidemia (peningkatan kadar trigliserida dan penurunan HDL).

Seseorang dikatakan mengalami sindrom metabolik jika mempunyai salah satu dari dua kriteria pertama dan dua dari empat kriteria terakhir, Dengan demikian kriteria sindrom metabolik berfokus tentang adanya toleransi glukosa terganggu atau yang disebut juga dengan diabetes mellitus, dan atau resitensi insulin yang didukung dengan paling sedikit dua faktor risiko lain yaitu hipertensi, dislipidemia, obesitas sentral dan mikro albuminaria (Adriansjah dan Adam, 2006).

Prevalensi sindrom metabolik lebih tinggi terjadi pada individu tidak aktif dan memiliki kebugaran kardiorespirasi yang rendah (Stabelini Neto et al., 2011). Definisi dari kebugaran jasmani itu sendiri diartikan sebagai kemampuan setiap orang dalam menjalani kehidupan setiap hari dan juga keadaan yang tak terduga yang dapat dijalaani dengan efektif tanpa merasakan kelelahan yang begitu berat dan masih memiliki cadangan energi untuk menikmati waktu ataupun bersantai (Werner, 2011: 19). Secara garis besar, kebugaran jasmani dapat dibagi ke dalam komponen keterampilan (skill related fitness) dan juga komponen kesehatan (health related fitness). Dwyer (2008: 3) menyatakan bahwa komponen kebugaran komponen yang terkait dengan kesehatan meliputi: (a) kebugaran kardiorespirasi, (b) komposisi tubuh, (c) fleksibilitas, (d) kekuatan otot dan (e) daya tahan otot. Sedangkan, komponen kebugaran jasmani yang berkaitan dengan keterampilan meliputi: (a) kecepatan, (b) kekuatan, (c) keseimbangan, (d) kelincahan, (e) koordinasi, dan (f) waktu reaksi.

Kebugaran jasmani seseorang dapat diperoleh, dipertahankan dan juga ditingkatkan dengan rutin menjalani olahraga ataupun aktivitas fisik secara teratur dan juga terukur (Setiawan et al., 2018). Olahraga ataupun aktivitas fisik yang dilakukan sesuai dengan dosis latihan akan memberikan dampak yang positif terhadap peningkatan berbagai komponen kebugaran jasmani dan juga memberikan perubahan pada system pernapasan dn jantung, kekuatan otot dan fleksibilitas sendi. Olahraga juga dapat mencegah dan juga mengurangi angka kejadian penyakit seperti obesitas, penyakit jantung dan pembuluh darah, diabetes mellitus (DM), tekanan darah tinggi, kelainan pada persendi, otot, tulang, dan juga stres (Damayanti, 2015).

Aktivitas fisik yang dilakukan secara rutin dapat menurunkan tekanan darah yang tinggi pada seseorang yang mengalami hipertensi. Selain itu, rutin berolahraga dapat meningkatkan stroke volume atau volume darah yang dipompa oleh jantung sekali denyutan, produksi sel darah merah juga meningkat akibat rutib berolahraga. Olahraga juga dapat menurunkan low-density lipoprotein (LDL) dan menaikkan high-density lipoprotein (HDL) serta mempercepat pemulihan setelah aktivitas fisik (Setiawan et al., 2018) dan (Taylor D, 2014). Lansia memiliki kekhususan dalam melakukan aktivitas fisik yang tidak bisa disamakan dengan orang pada umumnya. Latihan yang disarankan bagi lansia adalah olahraga yang dilakukan secara aerobik, latihan untuk kelentukan atau fleksibilitas, latihan untuk menjaga kekuatan otot serta latihan untuk menjaga keseimbangan. WHO telah memberikan panduan untuk melakukan aktivitas fisik setidaknya 150 menit dalam satu minggu dengan intensitas yang 
Jurnal Keolahragaan 9 (2), 2021 - 161

Prijo Sudibjo, Cerika Rismayanthi, Krisnanda Dwi Apriyanto

dilakukan adalah sedang, agar tujuan mendapatkan kesehatan bagi lansia dapat terpenuhi (Taylor D, 2014).

Perkembangan dari sindrom metabolik sangat dipengaruhi oleh aktivitas fisik yang dapat memberikan pengaruh terhadap obesitas serta distribusi lemak dan juga proses inflamasi yang berhubungan dengan risiko penyakit kardiorespirasi yang dapat dialami oleh para lansia. Seseorang yang memiliki tingkat aktivitas fisik yang rendah lebih berisiko untuk mengalami sindrom metabolik dua kali lebih besar jika dibandingkan seseorang yang memiliki aktivitas fisik yang baik (Katzmaryk. 2003) dan (Rennie KL. 2003). Aktivitas fisik yang dilakukan dengan intensitas sedang secara ilmiah dalam sebuah penelitian dikatakan dapat menurunkan tekanan darah tinggi pada pasien hipertensi esensial ringan hingga sedang. Berdasarkan pengembangan model latihan senam bagi lanjut usia guna menjaga kesegaran jasmani serta meningkatkan kemampuan fungsi otak yang dikembangkan oleh Putra, E., \& Suharjana, S., tahun 2018 menunjukkan kevalidan dalam model senam lansia yang telah disusun dan juga layak serta tepat guna bagi untuk kebuharan jasmani dan juga fungsi otak. Pengembangan senam bagi lansia tersebut, dikembangkan dengan waktu 29 menit 36 detik (30 menit), dan terdiri atas 25 gerakan didalamnya mengandung unsur warming up, latihan inti dari kebugaran jasmani, gerakan inti otak, serta cooling down. Latihan dilakukan dengan intensitas 70-80\% denyut nadi maksimal (Putra, E., \& Suharjana, S., 2018)

Hasil penelitian yang telah dilakukan oleh The Pawtucket Study memaparkan hasil bahwa aktivitas fisik memiliki hubungan yang signifikan terhadap meningkatnya kadar HDL. Sebuah penelitian lain yang telah dilakukan di Kanada, didapatkan hasil bahwa odds ratio (OR) aktivitas fisik yang baik untuk sindrom metabolik adalah 0,73 (95\% CI =0,54-0,98; nilai $\mathrm{p}<0,05)$ dibandingkan aktivitas fisik yang kurang baik (Susan EB, 2006). Sedangkan penelitian yang dilakukan oleh Rennie pada tahun 2003 memaparkan bahwa aktivitas fisik yang dilakukan dengan intensitas sedang dan juga intensitas tinggi dapat menurunkan angka kejadian sindrom metabolik dengan odds ratio 0,78 (95\% CI $=0,63 ; 0,96)$ pada aktivitas fisik intensitas sedang dan 0,52 (95\% CI = 0,40;0,67) pada intensitas tinggi. Walaupun demikian data tentang hubungan antara sindrom metabolik dengan komponen kebugaran lansia di Indonesia belum diketahui. Oleh karenanya penelitian ini memiliki tujuan untuk mengetahui hubungan antara sindrom metabolik dengan kebugaran kardiorespirasi, fleksibilitas, kekuatan, dan keseimbangan pada lansia.

\section{METODE}

Penelitian yang telah dilakuak ini merupakan penelitian observasionalanalitikan, dilakukan dengan pendekatan secara cross sectional. Subjek penelitian diambil dengan teknik consecutive sampling. Pengambilan data dilaksanakan di balai desa Nogotirto, Kelurahan Nogotirto, Kecamatan Gamping Sleman. Lansia yang mempunyai riwayat sakit jantung dan penyakit kronis yang berat tidak dapat ikut dalam penelitian.

Penentuan sindrom metabolik yaitu dengan mengukur tekanan darah, lingkar perut, trigliserida, HDL dan juga glukosa darah puasa. NCEP-ATP digunakan dalam menentukan apakah seseorang menderita sindrom metabolik atau tidak. Seseorang dikatakan menderita sindrom metabolik apabila memiliki paling sedikit tiga kriteria berikut:

a) Obesitas perut (lingkar pinggang $>88 \mathrm{~cm}$ untuk wanita dan untuk pria $>102 \mathrm{~cm}$ ),

b) Peningkatan kadar trigliserida darah ( $\geq 150 \mathrm{mg} / \mathrm{dL}$, atau $\geq 1,69 \mathrm{mmol} / \mathrm{L})$,

c) Penurunan kadar kolesterol HDL $(<40 \mathrm{mg} / \mathrm{dL}$ atau $<1,03 \mathrm{mmol} / \mathrm{L}$ pada pria dan pada wanita $<50$ $\mathrm{mg} / \mathrm{dL}$ atau $<1,29 \mathrm{mmol} / \mathrm{L})$,

d) Peningkatan tekanan darah (sistolik $\geq 130 \mathrm{mmHg}$, diastolik $\geq 85 \mathrm{mmHg}$ atau dalam konsumsi obat anti hipertensi),

e) Peningkatan glukosa darah puasa (kadar glukosa puasa $\geq 110 \mathrm{mg} / \mathrm{dL}$, atau $\geq 6,10 \mathrm{mmol} / \mathrm{L}$ atau dalam konsumsi obat anti diabetes) (Adult Treatment Panel III, 2001) dan Bloomgarden (2004).

Semua subjek penelitian diwajibkan mengikuti semua rangkaian penelitian yang dilakukan. Instrumen yang digunakan untuk mengumpulkan data berupa tes jalan 6 menit (6-minute walking test) untuk mengukur kapasitas kardiorespirasi, sit and reach untuk mengukur fleksibilitas, hand grip dynamometer dan leg and back dynamometer untuk mengukur kekuatan, serta berdiri satu kaki untuk mengukur keseimbangan.

Tabel di bawah ini adalah kisaran skor normal 6-Minute Walking test untuk laki-laki dan wanita, lansia yang mendapat skor di atas kisaran ini akan dianggap di atas rata-rata (above average) atau baik dan mereka yang di bawah kisaran sebagai di bawah rata-rata (below average) atau kurang. 
Jurnal Keolahragaan 9 (2), 2021 - 162

Prijo Sudibjo, Cerika Rismayanthi, Krisnanda Dwi Apriyanto

Tabel 1. Norma Normal 6-minute Walking Test (satuan meter)

\begin{tabular}{|c|c|c|c|c|}
\hline \multirow[t]{2}{*}{ No } & \multirow[t]{2}{*}{ Usia } & Laki-laki & Jenis kelamin & Perempuan \\
\hline & & Laki-laki & & Perempuan \\
\hline 1. & $60-64$ & $558-672$ & & $498-604$ \\
\hline 2. & $65-69$ & $512-640$ & & $457-581$ \\
\hline 3. & $70-74$ & $498-622$ & & $439-562$ \\
\hline 4. & $75-79$ & $430-585$ & & $393-535$ \\
\hline 5. & $80-84$ & $407-553$ & & $352-494$ \\
\hline 6. & $85-89$ & $347-521$ & & $311-366$ \\
\hline 7. & $90-94$ & $280-457$ & & $251-402$ \\
\hline
\end{tabular}

(Jones \& Ricli, 2002)

Norma dari berbagai komponen kebugaran jasmani: fleksibilitas, kekuatan otot tangan, kekuatan otot tungkai, kekuatan otot punggung dan keseimbangan dapat dilihat pada tabel-tabel di bawah ini.

Tabel 2. Norma Fleksibilitas dengan Sit and Reach Test (satuan cm)

\begin{tabular}{llccccc}
\hline \multirow{2}{*}{ No. } & \multirow{2}{*}{ Jenis kelamin } & \multicolumn{5}{c}{ Norma } \\
\cline { 2 - 6 } nangat baik & Baik & Sedang & Cukup & Kurang \\
\hline 1. & Laki-laki & $>14$ & $11-14$ & $7-10$ & $4-6$ & $<4$ \\
\hline 2. & Perempuan & $>15$ & $12-15$ & $7-11$ & $4-6$ & $<4$ \\
\hline
\end{tabular}

(Mackenzie, 2005)

Tabel 3. Norma Kekuatan Otot Tangan dengan Hand Grip Dynamometer (satuan kg)

\begin{tabular}{llccccc}
\hline \multirow{2}{*}{ No. } & \multirow{2}{*}{ Jenis kelamin } & Sangat baik & Baik & Sedang & Cukup & Kurang \\
\cline { 2 - 6 } 1. & Laki-laki & $>56$ & $51-56$ & $45-50$ & $39-44$ & $<39$ \\
\hline 2. & Perempuan & $>36$ & $31-36$ & $25-30$ & $19-24$ & $<19$ \\
\hline & & & & & (Mackenzie, 2005)
\end{tabular}

Tabel 4. Norma Kekuatan Otot Tungkai dengan Leg Dynamometer (satuan kg)

\begin{tabular}{llccccc}
\hline \multirow{2}{*}{ No. } & \multirow{2}{*}{ Jenis kelamin } & \multicolumn{5}{c}{ Norma } \\
\cline { 3 - 7 } 1. & Langat baik & Baik & Sedang & Cukup & Kurang \\
\hline 2. & Perempuan & $\geq 259,5$ & $187,5-159$ & $127,5-187$ & $84,5-127$ & $\leq 84$ \\
\hline
\end{tabular}

(Mackenzie, 2005)

Tabel 5. Norma Kekuatan Otot Punggung dengan Back Dynamometer (satuan kg)

\begin{tabular}{llccccc}
\hline \multirow{2}{*}{ No. } & \multirow{2}{*}{ Jenis kelamin } & Sangat baik & Baik & Sedang & Cukup & Kurang \\
\cline { 3 - 6 } & & $\geq 135,5$ & $112,5-153$ & $76,5-112$ & $52,5-75$ & $\leq 52$ \\
\hline Laki-laki & Perempuan & $\geq 103,5$ & $78,5-103$ & $57,5-78$ & $28,5-57$ & $\leq 28$ \\
\hline
\end{tabular}

(Mackenzie, 2005)

Tabel 6. Norma Keseimbangan dengan The Stork Test (satuan detik)

\begin{tabular}{llccccc}
\hline \multirow{2}{*}{ No. } & \multirow{2}{*}{ Jenis kelamin } & Sangat baik & Baik & Sedang & Cukup & Kurang \\
\cline { 2 - 6 } & & $>50$ & $37-50$ & $15-36$ & $5-14$ & $<5$ \\
\hline 1. & Laki-laki & $>27$ & $23-27$ & $8-22$ & $3-7$ & $<3$ \\
\hline 2. & Perempuan & &
\end{tabular}

(Mackenzie, 2005)

Teknik analisis data dalam penelitian meliputi analisis deskriptif untuk melihat distribusi kategori kapasitas fisik dan sindrom metabolik pada laki-laki dan perempuan. Dilakukan pula analisis untuk melihat kriteria kapasitas fisik berdasarkan norma pada tabel 9.

Selanjutnya dilakukan uji normalitas dengan menggunakan uji Kolmosgorof-smirnof. Hubungan antara kapasitas fisik dan sindrom metabolik dianalisis dengan uji korelasi untuk menilai hubungan antara sindrom metabolik dengan komponen kebugaran jasmani lansia yang meliputi kebugaran 
kardiorespirasi, kekuatan otot, fleksibilitas, dan keseimbangan dengan menggunakan uji korelasi Pearson bila data terdistribui normal atau uji korelasi Spearman bila data tidak terdistribusi normal. Pengambilan data pada penelitian ini telah mendapatkan Ethical Clearance dari Universitas Gadjah Mada nomor KE/FK/0323/EC/2019.

\section{HASIL DAN PEMBAHASAN}

Telah dilakukan pengukuran sebanyak 118 orang lansia untuk mengetahui adanya sindrom metabolik serta pengukuran tingkat kebugaran. Hasil menunjukkan bahwa sebanyak 32 (27\%) lansia yang terdiri atas 6 laki-laki dan 26 perempuan, mengalami sindrom metabolik. Sedangkan sejumlah 86 (73\%) lansia yang terdiri atas 27 laki-laki dan 59 perempuan tidak mengalami sindrom metabolik (tabel 1).

Tabel 7. Jumlah Lansia Berisiko SM berdasarkan Jenis Kelamin

\begin{tabular}{|c|c|c|c|c|c|c|c|}
\hline \multirow{2}{*}{ No. } & \multirow{2}{*}{ Jenis Kelamin } & \multicolumn{4}{|c|}{ Sindrom Metabolik } & \multicolumn{2}{|c|}{ Jumlah } \\
\hline & & $\mathrm{Ya}$ & $\%$ & Tidak & $\%$ & Angka & $\%$ \\
\hline 1. & Laki-laki & 6 & 18 & 27 & 82 & 33 & 100 \\
\hline 2. & Perempuan & 26 & 31 & 59 & 69 & 85 & 100 \\
\hline Jun & & 32 & 27 & 86 & 73 & 118 & 100 \\
\hline
\end{tabular}

Secara umum kriteria sindrom metabolik ditentukan ada tidaknya obesitas abdominal (lingkar), glukosa darah puasa, kadar trigliserida darah, kadar kolesterol HDL dan tekanan darah. Sindrom metabolik adalah seseorang dengan memiliki sedikitnya 3 kriteria sindrom metabolik.

Dari sejumlah 118 lansia yang mengikuti penelitian, hanya terdapat 70 lansia saja yang mampu mengikuti seluruh rangkaian antropometris, pemeriksaan laboratorium darah dan tes kebugaran jasmani yang dilakukan. Dari 70 lansia tersebut 51 lansia perempuan dengan rerata umur 63 tahun, dan 19 lansia laki-laki dengan rerata umur 60 tahun. Lansia yang mengikuti semua rangkaian tes dalam penelitian dapat dilihat pada tabel 2 berikut:

Tabel 8. Jumlah Lansia yang Mengikuti Semua Rangkaian Tes

\begin{tabular}{cccc}
\hline No & Jenis Kelamin & Jumlah & Rerata Usia \\
\hline 1. & Laki-laki & 19 & 60 \\
2. & Perempuan & 51 & 63 \\
\hline & Jumlah & 70 & \\
\hline
\end{tabular}

Hasil tes beberapa komponen tes kebugaran dari 70 lansia yang menyelesaikan seluruh rangkaian tes menunjukkan bahwa beberapa komponen kebugaran seperti kebugaran kardiorepirasi, kekuatan otot dan keseimbangan menunjukkan hasil yang kurang baik pada laki-laki maupun perempuan perempuan. Hanya satu komponen kebugaran (fleksibilitas) yang mempunyai nilai rata-rata yang sangat baik (tabel 9).

Tabel 9. Hasil Pengukuran beberapa Komponen Kebugaran Lansia

\begin{tabular}{|c|c|c|c|c|c|}
\hline \multirow{2}{*}{ No } & \multirow{2}{*}{ Komponen Kebugaran } & \multicolumn{2}{|c|}{ Laki-laki } & \multicolumn{2}{|c|}{ Perempuan } \\
\hline & & Rerata & Kategori & Rerata & Kategori \\
\hline 1. & Kardiorespirasi (m) & 336 & Kurang & 382 & Kurang \\
\hline 2. & Fleksibilitas $(\mathrm{cm})$ & 29 & Sangat baik & 28 & Sangat baik \\
\hline 3. & Kekuatan Otot Tangan & 21,3 & Kurang & 15,7 & Kurang \\
\hline 4. & Kekuatan Otot Tungkai & 33,5 & Kurang & 51,1 & Kurang \\
\hline 5. & Kekuatan Otot Punggung & 42,4 & Kurang & 48,1 & Kurang \\
\hline 6. & Keseimbangan & 3,2 & Kurang & 4,02 & Cukup \\
\hline
\end{tabular}




\section{Jurnal Keolahragaan 9 (2), 2021 - 164}

Prijo Sudibjo, Cerika Rismayanthi, Krisnanda Dwi Apriyanto

Dilakukan uji korelasi untuk menentukan adanya hubungan antara sindrom metabolik dengan beberapa komponen kebugaran jasmani. Uji normalitas dilakukan dengan uji Kolmogorov Smirnov. Data terdistribusi normal apabila $\mathrm{p}>0,05$. Berikut adalah hasil uji normalitas Kolmogorov Smirnov yang meliputi kebugaran kardiorespirasi, fleksibilitas, kekuatan otot tangan, kekuatan otot tungkai, kekuatan otot punggung dan keseimbangan (tabel 10).

Tabel 10. Hasil Uji Normalitas terhadap beberapa Komponen Kebugaran

\begin{tabular}{clcc}
\hline No. & \multicolumn{1}{c}{ Komponen Kebugaran } & Signifikansi & Keterangan \\
\hline 1. & Kardiorespirasi & .081 & Normal \\
2. & Fleksibilitas & .012 & Tidak Normal \\
3. & Kekuatan Otot Tangan & .000 & Tidak Normal \\
4. & Kekuatan Otot Tungkai & .000 & Tidak Normal \\
5. & Kekuatan Otot Punggung & .000 & Tidak Normal \\
6. & Keseimbangan & .000 & Tidak Normal \\
\hline
\end{tabular}

Pada data fleksibilitas kekuatan otot tangan, tungkai, punggung dan keseimbangan tidak berdidtribusi normal, sehingga uji parametrik Pearson tidak dapat dilakukan. Uji yang dapat dilakukan pada data yang tidak berdistribusi normal adalah uji non parametrik Spearman. Berikut adalah hasil uji korelasi non parametrik Spearman (tabel 11).

Tabel 11. Hasil Uji Non Parametrik Spearman terhadap beberapa Komponen Kebugaran

\begin{tabular}{|c|c|c|c|c|}
\hline \multirow{3}{*}{ No. } & \multirow{3}{*}{ Komponen Kebugaran } & \multicolumn{3}{|c|}{ Spearman's rho } \\
\hline & & \multicolumn{3}{|c|}{ SM } \\
\hline & & Correlation Coefficient & Sig. (2-tailed) & $\mathrm{N}$ \\
\hline 1. & Kardiorespirasi & -.197 & .103 & 70 \\
\hline 2. & Fleksibilitas & -.084 & .488 & 70 \\
\hline 3. & Kekuatan Otot Tangan & -.225 & .061 & 70 \\
\hline 4. & Kekuatan Otot Tungkai & -.295 & $.013^{*}$ & 70 \\
\hline 5. & Kekuatan Otot Punggung & -.101 & .405 & 70 \\
\hline 6. & Keseimbangan & -.282 & $.018^{*}$ & 70 \\
\hline
\end{tabular}

Tabel 11 juga menunjukkan adanya hubungan antara sindrom metabolik dengan kekuatan tungai $(\mathrm{p}=0,013)$ dan keseimbangan $(\mathrm{p}=0,018)$, namun tidak terdapat hubungan antara sindrom metabolik dengan kekuatan peras tangan, kekuatan otot punggung, kebugaran kardiorespirasi dan fleksibilitas ( $\mathrm{p}$ $>0,05$ ). Tanda korelasi negatif memiliki makna bahwa lansia yang terdiagnosis mengalami sindrom metabolik cenderung mengalami pelemahan kekuatan tungkai dan penurunan keseimbangan.

\section{Pembahasan}

Kebugaran jasmani menjadi tolak ukur yang penting bagi kesehatan manusia pada setiap kelompok umur, termasuk lansia. Seseorang yang memiliki tingkat kebugaran jasmani yang baik akan memiliki tingkat efektivitas dan produktivitas kerja yang tinggi. Selain agar terhindar dari cedera akibat melakukan aktivitas fisik sehari-hari, kebugaran jasmani juga mampu meningkatkan efektivitas dan produktivitas kerja lansia. Lansia akan lebih sehat, mandiri dan tidak tergantung kepada orang lain.

Pada penelitian ini komponen kebugaran jasmani yang diukur adalah kebugaran kardiorespirasi, fleksibilitas, kekuatan (tangan, tungkai dan punggung) serta keseimbangan. Hasil penelitian menunjukkan bahwa kebugaran jasmani pada laki-laki menunjukkan tingkat kebugaran kardiorespirasi berada pada kategori kurang, fleksibilitas berada pada kategori sangat baik, kekuatan tangan berada pada kategori kurang, kekuatan tungkai berada pada kategori kurang, kekuatan punggung berada pada kategori kurang serta keseimbangan juga memiliki kategori kurang. Sedangkan tingkat kebugaran jasmani pada perempuan menunjukkan komponen kardiorespirasi berada pada kategori kurang, fleksibilitas berada pada kategori sangat baik, kekuatan tangan berada pada kategori kurang, kekuatan tungkai berada pada kategori kurang, kekuatan punggung berada pada kategori kurang serta keseimbangan memiliki kategori cukup. Fleksibilitas yang sangat baik akan mendukung lansia untuk terhindar dari kemungkinan terjadinya cedera saat melakukan aktivitas fisik harian. Sedangkan kekuatan otot, keseimbangan dan kebugaran kardiorespirasi yang masih kurang sangat mungkin terjadi karena olahraga yang dilakukan oleh kelompok lansia ini kurang berefek pada kekuatan otot dan komponen kardiorespirasi. 
Hasil penelitian pada indikator sindrom metabolik dari 118 lansia, menunjukkan bahwa sebanyak 32 (27\%) lansia yang terdiri atas 6 laki-laki dan 26 perempuan, menunjukkan adanya sindrom metabolik. Sedangkan sejumlah 86 (73\%) lansia yang terdiri atas 27 laki-laki dan 59 perempuan tidak menunjukkan adanya sindrom metabolik. Dalam penelitan ini seseorang mengalami sindrom metabolik jika menderita paling sedikit tiga kriteri dari sindrom metabolik itu sendiri. Kriteria sindrom metabolik telah disebutkan di atas berdasarkan NCEP-ATP.

Penelitian yang telah dilakukan ini, menunjukkan hasil bahwa ada hubungan yang bermakna antara sindrom metabolik dan kekuatan tungkai $(l e g)$. Segala aktivitas fisik yang dilakukan setiap saat selalu melibatkan peran otot-otot tungkai. Kita berjalan, berlari, melompat, meloncat, duduk, jongkok dan aktivitas lainnya membutuhkan kekuatan otot tungkai. Lansia yang memiliki kekuatan otot tungkai yang baik mampu meningkatkan mobilitas gerak sehingga efektivitas dan produktivitas hidupnya meningkat. Lansia akan memiliki tingkat kepercayaan diri dan juga keyakinan yang tinggi dalam melakukan berbagai aktivitas fisik sehari-hari apabila didukung oleh kekuatan otot tungkai yang baik. Diketahui bahwa aktivitas fisik yang dilakukan secara teratur mampu menurunkan prevalensi sindrom metabolik dan meningkatkan kebugaran jasmani dan kesehatan lansia (Setiawan et al., 2018).

Hasil penelitian yang telah dilaporkan oleh Vieira et al (2013) dengan tujuan untuk membandingkan parameter metabolik, kelenturan, kekuatan otot, kapasitas fungsional, dan kekuatan otot tungkai bawah wanita lanjut usia dengan dan tanpa sindrom metabolik menunjukkan bahwa wanita dengan sindrom metabolik mempunyai kapasitas fungsional dan kekuatan otot yang lebih rendah jika dibandingkan dengan wanita tanpa sindrom metabolik. Demikian pula hasil penelitian yang dilakukan oleh Penninx et al., (2009), dalam studi tindak lanjut 4,5 tahun dengan wanita dan pria lanjut usia menunjukkan adanya hubungan yang kuat antara keterbatasan mobilitas dan jumlah komponen sindrom metabolik. Hal ini menunjukkan bahwa keterlibatan otot tungkai yang diperlukan untuk melakukan aktivitas sehari-hari dapat mempengaruhi kejadian sindrom metabolik. Sebagai alternatif latihan kekuatan otot, dapat dilakukan dengan latihan bodyweight yang sudah terbukti mempunyai dampak pengaruh yang signifikan terhadap peningkatan kekuatan otot (tungkai, punggung, tangan), kekuatan menarik otot lengan, serta kekuatan mendorong otot lengan (Nasrulloh, A., \& Wicaksono, I., 2020).

Temuan penting lainnya adalah bahwa wanita lanjut usia tanpa sindrom metabolik menunjukkan kekuatan otot dan kekuatan otot relatif lebih besar. Pernyataan ini sesuai dengan hasil penelitian yang dilakukan oleh Tibana et al., (2005) yang menunjukkan bahwa wanita paruh baya tanpa sindrom metabolik memiliki kekuatan otot relatif lebih besar yang dinilai dengan kekuatan genggaman tangan jika dibandingkan dengan wanita dengan sindrom metabolik. Peneliti lain, Radim et al (2005) yang menguji hubungan antara kekuatan otot dan kejadian sindrom metabolik, menunjukkan bahwa kekuatan otot secara independen terkait dengan kejadian sindrom metabolik pada pria sehat. Kekuatan otot dapat melindungi dari perkembangan sindrom metabolik.

Paparan hasil dalam penelitian ini juga mengemukakan ada korelasi yang bermakna antara sindrom metabolik dan keseimbangan. Hal ini menunjukkan bahwa seseorang dengan keseimbangan yang baik memilik sistem saraf yang baik. Ketika otak mampu mengontrol keseimbangan tubuh dengan baik, maka ketika melakukan aktivitas fisik juga lebih maksimal dan meminimalisir cedera akibat terjatuh karena aktivitas fisik. Tubuh kita memiliki pusat pengaturan keseimbangan yang berada di otak kecil (cerebellum). Cerebellum adalah bagian dari susunan saraf pusat yang terletak di atas batang otak yang memiliki fungsi utama untuk mengatur gerakan dan keseimbangan serta membantu mempelajari dan mengingat keterampilan motorik.Perkembangan keseimbangan tubuh juga dipengaruhi oleh sistem informasi sensorik, respons sinergis saraf sensorik, kekuatan otot, sistem adaptasi, dan gerakan sendi (Purwo, Anita dan Rizka, 2018). Keseimbangan merupakan dasar dari semua gerakan yang merupakan kemampuan tubuh untuk memberikan posisi yang diinginkan serta dapat memiliki efek positif pada kehidupan sehari-hari serta efek penting untuk beberapa sifat motorik (Hakan \& Nebahat, 2019). Keseimbangan merupakan masalah yang cukup serius bagi lansia, karena dapat mempengaruhi mobilitas sehari-hari.

Paparan hasil dalam penelitian ini menunjukkan tidak ada korelasi antara sindrom metabolik dan kardiorespirasi. Meskipun dalam penelitian ini tidak menunjukkan hubungan yang bermakna antara sindrom metabolik dan kebugaran kardiorespirasi, tetapi perlu ditekankan bahwasannya tingkat kebugaran kardiorespirasi lansia baik laki-laki maupun perempuan berada pada kategori rendah. Hasil penelitian ini dapat dijadikan rekomendasi bagi lansia untuk tetap menjaga kebugaran kardiorespirasi dengan melakukan berbagai aktivitas fisik sehingga kebugaran dan kesehatan tetap terjaga. Hasil 
penelitian yang telah dilakukan oleh Stabelini Neto et al. (2011) dengan tujuan untuk menganalisis hubungan aktivitas fisik dan tingkat kebugaran kardiorespirasi dengan sindroma metabolik pada remaja Brazil menunjukkan bahwa prevalensi sindrom metabolik lebih tinggi di antara remaja Brasil tidak aktif dan memiliki kebugaran kardiorespirasi yang rendah dan terdapat hubungan yang signifikan antara sindrom metabolik dan kebugaran kardiorespirasi. Ini menunjukkan bahwa strategi pencegahan jangka panjang harus dikembangkan untuk meningkatkan aktivitas fisik dan kebugaran kardiorespirasi di awal kehidupan dengan tujuan mempromosikan gaya hidup aktif secara fisik sehingga mampu mencegah sindrom metabolik.

Lansia merupakan kelompok yang memerlukan perhatian dan perlakuan yang khusus dalam hal kesehatan dan sosial. Aktivitas fisik, tingkat kebugaran, fungsi fisiologis dan kesehatan lansia akan menurun seiring dengan bertambahnya usia. Kebugaran jasmani dapat meningkat apabila seseorang melakukan latihan sesuai dengan dosis yang dianjurkan (Setiawan et al., 2018). Aktivitas fisik yang teratur juga dapat meningkatkan kesehatan serta membantu mencegah penyakit (Blair \& Church, 2004). Beberapa penelitian menunjukkan bahwa orang dewasa yang aktif secara fisik lebih sehat dan memiliki kebugaran jasmani yang lebih tinggi daripada orang dewasa yang tidak aktif di berbagai negara dan kelompok populasi (Kuh et al., 2005). Dengan demikian aktivitas fisik sangat direkomendasikan untuk meningkatkan kesehatan dan kebugaran jasmani sebagai salah satu upaya menerapkan gaya hidup sehat. Penelitian juga menunjukkan bahwa aktivitas fisik dapat mempengaruhi kebugaran dan kesehatan dan bahwa hubungannya juga bersifat timbal balik (Kuh et al., 2005).

\section{SIMPULAN}

Komponen kebugaran kardiorespirasi lansia dapat ditingkatkan dengan memberikan latihan fisik dengan durasi lama dan intensitas tinggi sangat berisiko karena lansia sudah mengalami kemunduran fisik dan fungsional organ-organ tubuh. Kekuatan otot tungkai dan keseimbangan merupakan komponen kebugaran yang diperlukan agar lansia dapat melakukan aktivitas sehari-hari dengan risiko jatuh yang kecil. Kekuatan otot tungkai dan keseimbangan berhubungan dengan kejadian sindrom metabolik. Sehingga pada lansia yang sudah mengalami kemunduran fisik dan fungsional perlu melakukan latihan yang dapat memperkuat otot tungkai dan memperbaiki keseimbangan lansia.

\section{DAFTAR PUSTAKA}

Adriansjah, H dan Adam, J. (2006). Sindroma Metabolik: Pengertian, Epidemiologi, dan Criteria Diagnosis. Informasi laboratorium prodia No.4/2006.

Antonio Stabelini Neto, Jeffer E Sasaki, Luis PG Mascarenhas, Margaret CS Boguszewski, Rodrigo Bozza, Anderson Z Ulbrich, Sergio G da Silva and Wagner de Campos. (2011). Physical activity, cardiorespiratory fitness, and metabolic syndrome in adolescents: A crosssectional study. BMC Public Health, 11:674

Blair SN, Church TS. (2004). The fitness, obesity, and health equation: is physical activity the common denominator? JAMA. 2004; 292(10):1232-4.

Bloomgarden ZT,. (2004). Definitions of the insulin resistance syndrome: the 1st World Congress on the Insulin Resistance Syndrome. Diabetes Care. 2004 Mar;27(3):824-30.

Damayanti, S. (2015). Hubungan antara Frekuensi Senam Diabetes Mellitus dengan Kadar Gula Darah, Kadar Kolesterol dan Tekanan Darah pada Klien Diabetes Mellitus Tipe 2 di Kelompok Persadia RS Jogja. Jurnal Medika Respati. Vol. X Nomor 2 April 2015. ISSN: 1907 -3887

Dwyer, G.B. and Davis, S.E. (2008). ACSM's Health Related Physical Fitness Assessment Manual. American College of Sport Medicine: USA.

Hakan Acar \& Nebahat Eler. (2019). The Effect of Balance Exercises on Speed and Agility in Physical Education Lessons. Universal Journal of Educational Research 7(1): 74-79. DOI: 10.13189/ujer.2019.070110

International Diabetes Federation (IDF). (2006). The IDF worldwide definition of the metabolic syndrome. Belgium. 
Jones C.J., and Rikli R.E. (2002). Measuring Functional Fitness Of Older Adults, The Journal on Active Aging, March April 2002, pp. 24-30.

Katzmaryk. (2003). Targeting the metabolic syndrome with exercise: evidence from the heritage family study. Med. Sci. Sports Exerc. 2003; 35 (10): 1703-9.

Kaur JA. (2014). Comprehensive review on metabolic syndrome. Cardiol Res Pract. 2014:943162

Khan R, Buse J, Ferrannini E, Stern M. (2005). The metabolic Syndrome: Time for a Critical Appraisal: Join Statement from the American Diabetes Association and the European Association for the Study of Diabetes. Diabetes Care 2005; 28: 2289-2304

Kuh D, Bassey EJ, Butterworth S, Hardy R, Wadsworth ME. (2005). Grip strength, postural control, and functional leg power in a representative cohort of british men and women: associations with physical activity, health status, and socioeconomic conditions. J Gerontol A BiolSci Med Sci. 2005;60(2): 224-31.

Mackenzie, B. (2005). 101 Performance Evaluation Tests. London: Electric Word plc.

Nasrulloh, A., \& Wicaksono, I. (2020). Latihan bodyweight dengan total-body resistance exercise (TRX) dapat meningkatkan kekuatan otot. Jurnal Keolahragaan, 8 (1), 52 - 62. doi: https://doi.org/10.21831/jk.v8i1.31208

National Cholesterol Education Program criteria modifiedfor Asians (NCEP ATP III) Expert Panel on Detection, Evaluation, and Treatment of High Blood Cholesterol in Adults. (2001). Executive Summary of the Third Report of the National Cholesterol Education Program (NCEP) Expert Panel on Detection, Evaluation, and Treatment of High Blood Cholesterol in Adults (Adult Treatment Panel III). JAMA. 2001; 285: 2486-97.

Penninx BW, Nicklas BJ, Newman AB, et al. (2009). Metabolic syndrome and physical decline in older persons: results from the Health, Aging and Body composition study. J Gerontol A Biol Sci Med Sci. 2009;64: 96-102.

Purwo Sri Rejeki, Anita Faradilla Rahim, Rizka Eka Prasetya. (2018). Effect of Physical Training Towards Body Balance in Overweight Condition. Biomolecular And Health Science Journal. November, 01 (02)

Putra, E., \& Suharjana, S. (2018). Model senam lansia untuk kebugaran jasmani dan fungsi otak. Jurnal Keolahragaan, 6(2), 120-129. doi: https://doi.org/10.21831/jk.v0i0.20626

Radim et al. (2005). Association of Muscular Strength with Incidence of Metabolic Syndrome in Men. Medicine \& Science in Sports \& Exercise. DOI: 10.1249/01.mss.0000175865.17614.74.

Rennie KL. (2003). Association of the metabolic syndrome with both vigorous and moderate physical activity. International Journal of Epidemiology. 2003; 32: 600-6.

Setiawan et al. (2018). Correlation Physical Activity, Energy Balance, and Metabolic Syndrome of Physical Fitness in Elderly Age Group. Majalah Kedokteran Bandung, Volume 50 No. 1, Maret 2018

Susan EB. (2006). Physical activity and the metabolic syndrome in Canada. Appl. Physiol. Nutr. Metab. 2006; 31: 40-7

Taylor Denise. (2014). Review: Physical activity is medicine for older adults. Postgrad Med J 2014; 90:26-32.

Tibana RA, Tajra V, Cesar D, et al. (2011). Comparison of muscle strength between Brazilian women with and without metabolic syndrome. ConScientiae Saúde. 2011;10:708-714 Portugese.

Vieira et al. (2013). Decreased functional capacity and muscle strength in elderly women with metabolic syndrome. Clinical Interventions in Aging 2013:8 1377-1386

Werner W. K. H. and Sharon A. H. (2011). Lifetime Physical Fitness and Wellness. Wadsworth: United State of America.

Widjaya A. (2004). Obesitas dan Sindrom Metabolik. Jurnal Cardiology. 2(4): 1-16.

Copyright @ 2021, Jurnal Keolahragaan, ISSN 2339-0662 (print), ISSN 2461-0259 (online) 